\title{
Thermodynamic Analysis of Turbo-Charged Power Generating System
}

\author{
Captain Ehoda, Bassey B. Okon and Etimbuk B. Bassey \\ Department of Mechanical Engineering, Akwa Ibom State University, PMB 1167, Uyo, Nigeria
}

\begin{abstract}
Turbochargers have been known in compression ignition engines for power generation. Recent trends in power generation through gas cycles have recorded successes via turbochargers application in spark ignition engines as well. When power cycles are turbocharged, there is a general expectation of a higher power and performance output from the cycle as compared to when they are naturally aspirated. This research was conducted to estimate the thermodynamic properties of a spark ignition engine power generating system when it is both naturally aspirated and when the same system is turbocharged to 2.5 times the amount of air in natural aspiration. Octane fuel was employed for petrol approximation during this study. The system process was broken down into stages of charging between natural aspiration and turbocharged; thus MATLAB program was applied to model the system for the case of natural aspiration and turbocharging with no increase in fuel supply. The results were used for both analyses and comparison which showed that the system generates slightly more power with turbocharging at $0 \%$ increase in fuel consumption. The natural aspiration achieved values are $2.8232 \mathrm{~kJ} / \mathrm{mol}$ and $55.26 \%$ for output and efficiency respectively, while the turbocharged engine produced optimal values of $2.8833 \mathrm{~kJ} / \mathrm{mol}$ and $56.51 \%$ for output and efficiency. The air fuel ratio by mole for the turbocharged engine was $145.18: 1$, which shows a greater fuel economy of $59 \%$ as compared to the $59.5: 1 \mathrm{~A} / \mathrm{F}$ (air/fuel) ratio of the naturally aspirated engine.
\end{abstract}

Key words: Fuel, IC (internal combustion) engine, natural aspiration, spark ignition engine, turbocharger.

\section{Introduction}

Over the years, energy optimization in diesel power cycles has been achieved using turbocharging mechanism. In contrast, few turbocharged petrol engines have been built until recently and it is unlikely that a large fraction of the world's petrol engines will be so equipped. It is the difference in the combustion system between diesel and petrol engines that prevent the full potential of turbocharging from being obtained on the later. The turbocharging system was invented in the early 20th Century by Alfred Büchi, a Swiss engineer and the head of diesel engine research at Gebruder Sulzer engine manufacturing company [1]. There are two types of forced induction in naturally aspirated engines turbochargers and superchargers. Essentially, turbochargers are more efficient than superchargers as they work on the exhaust gas power while a supercharger operates on the power derived

Corresponding author: Engr. Dr. Bassey B. Okon, Doctor, research field: mechanical systems engineering. from the engine crankshaft. Engines fitted with these power optimizing systems provide a greater efficiency in terms of power \& fuel economy [2].

IC (internal combustion) engines are turbocharged to gain an increase in power output. Since the power of an engine is approximately proportional to the quantity of fuel burnt, the increase in power will require the supply of more fuel and charge air. In naturally aspirated engine, the quantity of air delivered to the cylinders is limited by the swept volume. Therefore, to increase the mass of air within this volume, an external means of supplying air to the cylinders will be necessary [3-5]. In practice, a compressor or blower is used to provide the needed air. The air being under pressure allows a greater mass to be contained in the cylinders and hence burning of more fuel will be mandatory to give the increased power output. The process of compression will raise the temperature of the air and lower its density [6].

Turbocharging systems were originally known as turbosuperchargers when all forced induction devices 
were classified as superchargers. In recent times, the term "supercharger" is usually applied to only mechanically driven forced induction devices. The key difference between a turbocharger and a conventional supercharger is that the later is mechanically driven by the engine, often through a belt connected to the crankshaft, whereas a turbocharger is powered by a turbine driven by the engine's exhaust gas [7]. Compared to a mechanically driven supercharger, turbochargers tend to be more efficient. Mechanisms involving turbocharging are commonly used on truck, car, train, aircraft, and construction equipment engines that run on diesel as fuel, that is, compression ignition engines.

Exhaust-gas turbocharging uses the hot exhaust gas from the engine, which is otherwise released into the environment with a high content of unused energy to drive the compressor that provides the air. Typically, charging is used only in diesel engines as the increased air in the combustion chamber allows for more fuel combustion and greater power output since the naturally aspirated engine would not burn all the fuel. However, turbo charging a fuel engine would yield advantages such as having the fuel efficiency of compression ignition engines and the low emission levels from the spark ignition engines. This is in addition to the better performance at higher altitudes.

\section{Research Methods}

Literature search was employed in this study. The literature review was aimed at identifying key issues relating to turbocharging IC engines and the limitations of the process. Research was conducted to estimate the general effects and the desirability of turbocharging IC engines, and the adversity that may arise from it; including the $\mathrm{NO}_{\mathrm{x}}$ and $\mathrm{SO}_{\mathrm{x}}$ outputs. In addition, MATLAB algorithm was generated in favour of the flowchart in Fig. 1.

The work output from, or input to a turbo-machine with single inlet and exhaust ports was derived from the first law of thermodynamics, following the steady state energy equation as:

$$
\begin{gathered}
\dot{Q}-\dot{w}=\dot{m}\left\{\left(h_{2}+k e_{2}+p e_{2}\right)-\right. \\
\left.\left(h_{1}+k e_{1}+p e_{1}\right)\right\}
\end{gathered}
$$

where:

$$
\begin{aligned}
& \dot{Q}=\text { heat transfer rate ( }+ \text { to the system) } \\
& \dot{w}=\text { work transfer rate (- to the system) } \\
& \dot{m}=\text { mass flow rate } \\
& h=\text { specific enthalpy } \\
& k e=\text { specific kinetic energy } \\
& p e=\text { specific potential energy } \\
& \text { Suffixes } 1,2=\text { inlet/exhaust ports }
\end{aligned}
$$

Further information on the developed flowchart is presented in Fig. 1.

\section{Data Collection}

Data used for the modelling and analyses were achieved from approved textbooks and research journals from experts in this field. The approximations for fuel and air internal thermodynamic properties were obtained from standard thermodynamic tables [8]. Secondary data were extracted from Rajeevan et al. [6] and Mohd and Manoj [9].

The specifications of the engine used in this research are presented in Table 1.

\section{Results and Discussion}

The outcomes from this investigation are presented in Tables 2-5. Further discussions regarding the implications of these outcomes are presented in the subsequent sections of this study.

The results in Tables 2 and 3 showed the optimal characteristics of the system when it has no turbocharger applied on it. The system is seen to produce a maximal cycle work of 2,823.2 J/mol of fuel consumption. The maximum pressure (working pressure) is observed at point 5, the point just after the instantaneous combustion of the fuel within the cylinder and is found as $10,644.20 \mathrm{kPa}$ (approximately $106 \mathrm{bar}$ ) with a corresponding temperature of 3,683.84 K. The thermodynamic plot of the system in Fig. 2 shows pressure-volume $(P-V)$ relationship of the system during natural aspiration. 


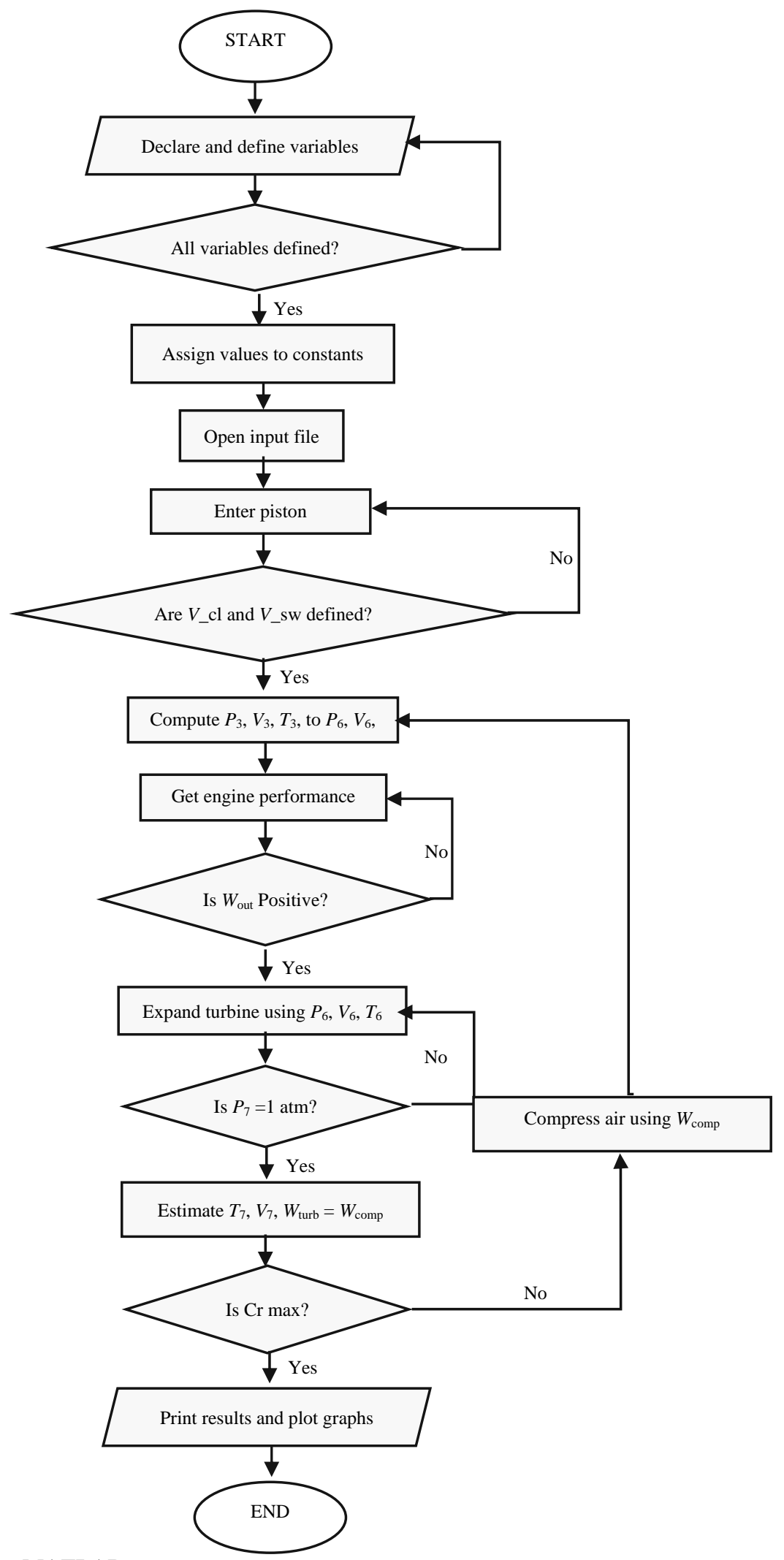

Fig. 1 Flowchart of the MATLAB program.

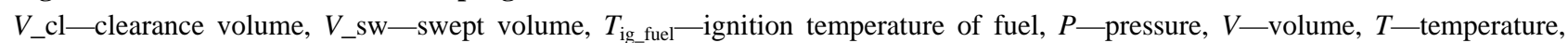
$W_{\text {out }}$-work output, $C r$-compression ratio, $W_{\text {tur }}$-turbine work, $W_{\text {comp }}$ - compressor work, $T_{\min }$-minimum piston temperature. 
Table 1 Engine dimensions and operational parameters.

\begin{tabular}{lll}
\hline S/N & Quantity & Value \\
\hline 1 & Bore & $0.07 \mathrm{~m}$ \\
2 & Stroke & $0.09 \mathrm{~m}$ \\
3 & Length of connecting rod & $0.1973 \mathrm{~m}$ \\
4 & Compression ratio for natural aspiration & $1: 8.5$ \\
5 & Inlet valve opening time & $10^{\circ}$ CA BTDC \\
6 & Inlet valve closing time & $50^{\circ}$ CA ABDC \\
7 & Exhaust valve opening time & $40^{\circ}$ CA BBDC \\
8 & Exhaust valve closing time & $10^{\circ}$ CA ATDC \\
9 & Ignition time & $10^{\circ}$ CA BTDC \\
10 & Ambient pressure & 101,300 Pa \\
11 & Ambient temperature & $298 \mathrm{~K}$ \\
\hline CA—crank angle; BTDC-before top dead centre; ABDC-after bottom dead centre; BBDC—before bottom dead centre;
\end{tabular}
ATDC—after top dead centre.

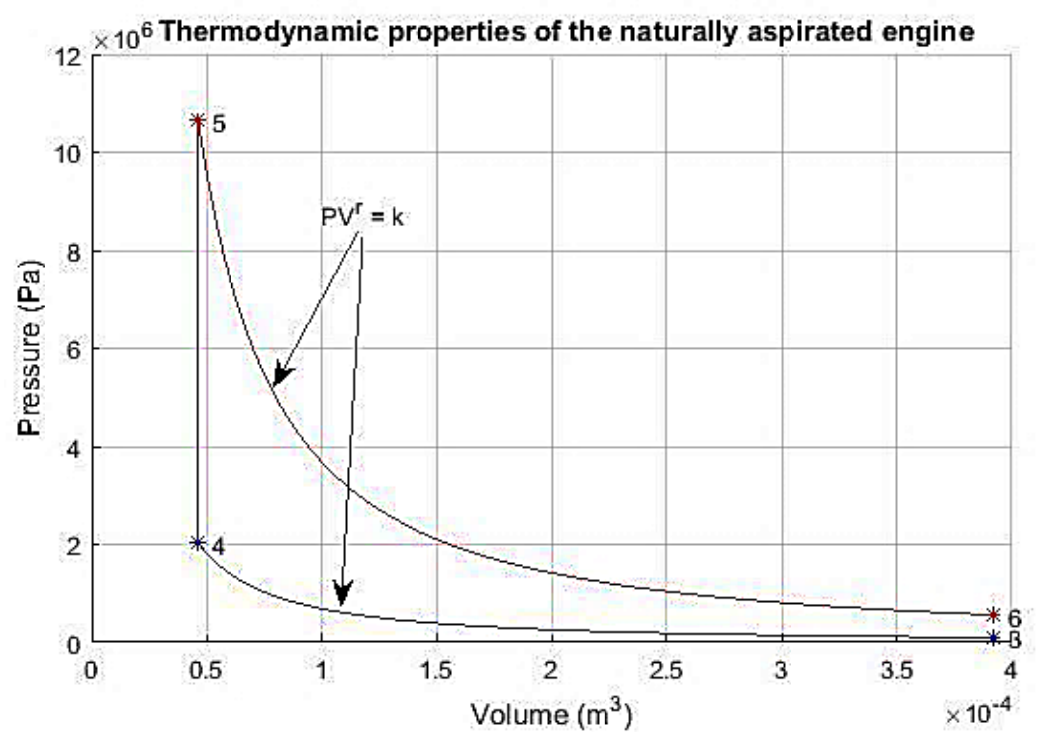

Fig. 2 The $P-V$ relationship of the naturally aspirated system.

Table 2 Thermodynamic characteristics of the system at natural aspiration.

\begin{tabular}{llllllll}
\hline Reference points & 1 & 2 & 3 & 4 & 5 & 6 & 7 \\
\hline Pressure $(\mathrm{kPa})$ & 101.30 & 101.30 & 101.30 & $2,026.73$ & $10,644.20$ & 560.23 & 101.30 \\
Volume $\left(\times 10^{-5} \mathrm{~m}^{3}\right)$ & 39.25 & 39.25 & 39.25 & 4.62 & 4.62 & 39.25 & 34.64 \\
Temperature $(\mathrm{K})$ & 298.00 & 298.00 & 298.00 & 701.43 & $3,683.84$ & $1,648.05$ & $1,032.91$ \\
\hline
\end{tabular}

Table 3 Performance characteristics of the system at natural aspiration.

\begin{tabular}{ll}
\hline Property & Value \\
\hline A/F (air/fuel) ratio by mole & $59.5: 1$ \\
Cycle work done (kJ/mol) & 2.8232 \\
Cycle efficiency & 0.5526 \\
\hline
\end{tabular}

Table 4 Thermodynamic characteristics of the system at turbocharging.

\begin{tabular}{llllllll}
\hline Reference points & 1 & 2 & 3 & 4 & 5 & 6 & 7 \\
\hline Pressure $(\mathrm{kPa})$ & 101.30 & 444.42 & 177.77 & $3,556.65$ & $5,281.82$ & 270.24 & 101.30 \\
Temperature $(\mathrm{K})$ & 298.00 & $1,307.38$ & 522.95 & $1,230.92$ & $1,827.98$ & 794.98 & 603.94 \\
\hline
\end{tabular}


Table 5 Performance characteristics of the system at turbocharging.

\begin{tabular}{ll}
\hline Property & Value \\
\hline A/F ratio by mole & $145.18: 1$ \\
Cycle work done $(\mathrm{kJ} / \mathrm{mol})$ & 2.8833 \\
Cycle efficiency & 0.5651 \\
\hline
\end{tabular}

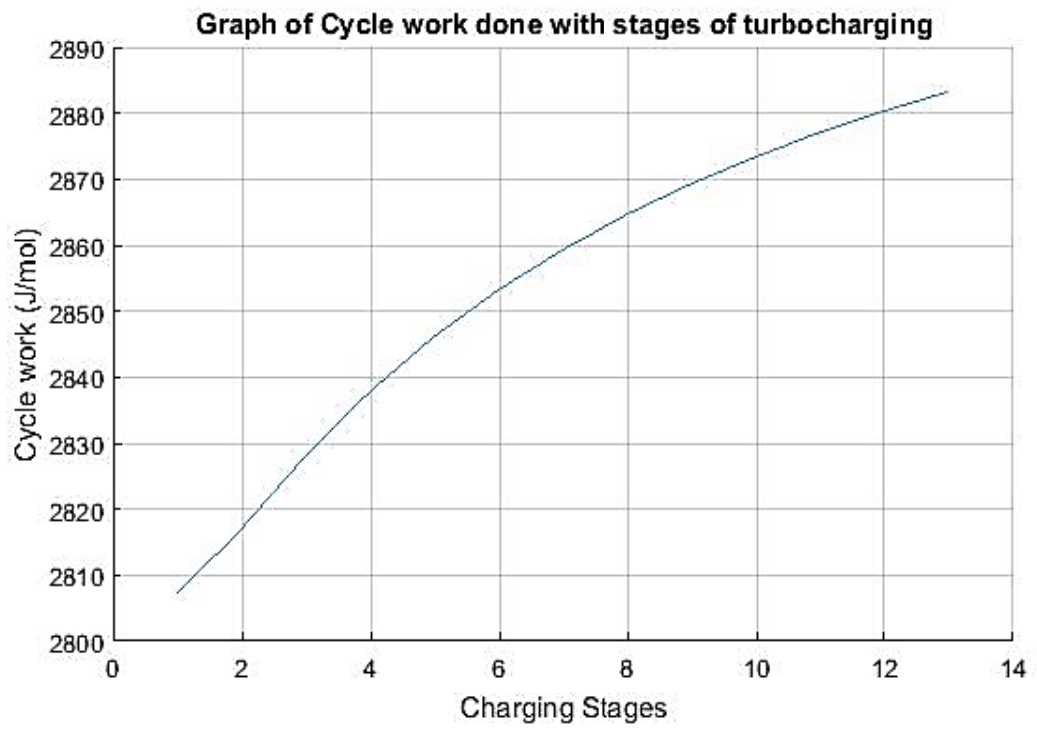

Fig. 3 Cycle work increases with charging.

For turbocharging, the air is supplied to the cylinder with no increase in the fuel supply so there is excess air for the combustion reaction. This can be done for up to 2.618 times the original mass of air in the combustion chamber [9]. The introduction of the turbocharger gave a performance boost to the naturally aspirated system. The optimal values obtained from turbocharging the engine (from the program feedback) are further shown in Tables 4 and 5.

As reflected in Table 5, a hike in the air input into the combustion chamber produced increase in work output from the $2.8232 \mathrm{~kJ} / \mathrm{mol}$ of the natural aspiration to $2.8833 \mathrm{~kJ} / \mathrm{mol}$. The cycle efficiency also increased from the $55.26 \%$ of natural aspiration to $56.51 \%$. The highest achievement however is in the fuel economy as A/F ratio spikes to $145.18: 1$. This is an amazing 59\% increase in fuel economy.

Similarly, Fig. 3 shows the changes in the system cycle work with stages of turbocharging until optimization.

The curve of correlation appears due to the exponential effect of the changing adiabatic index of the exhaust gas on the work done by the system. This change is a direct reflection of the changes in the $\mathrm{A} / \mathrm{F}$ ratio which comes from excess air being supplied than the fuel. It can further be deduced from mathematical relationship that the Otto cycle efficiency is directly proportional to the compression ratio of the cylinder, as long as other constants are unchanging $[9,10]$. The toll on the system is not however, without consequences as there is a notable pressure and temperature drop in the system [11].

\section{Conclusion}

This research was performed to estimate the thermodynamic properties of the system naturally and when turbocharged. As evident in the results, the system generates more power with turbocharging at $0 \%$ increase in fuel consumption. The theoretical combustion follows standard combustion equation, thereby giving rise to oxygen rich exhaust gases that leave no room for CO (carbon monoxide) formation with no fuel increment. Thus, the amount of CO formed in the exhaust is 0 PPU (parts per unit) at 
worst state of the engine combustion. For the turbocharged system, great performance leaps in all the parametric values are found. As the mass density and therefore charge volume increase by 2.5 times the original mass density, the cycle work increases from $2.8232 \mathrm{~kJ} / \mathrm{mol}$ of the natural aspiration to 2.8833 $\mathrm{kJ} / \mathrm{mol}$, and the cycle efficiency from $55.26 \%$ to $56.51 \%$. The economy of fuel was the highest feat achieved as 59\% increase in fuel economy was recorded.

\section{Acknowledgment}

The authors wish to express profound gratitude to the Department of Mechanical Engineering, Akwa Ibom State University in Nigeria for allowing this research to be conducted in their laboratory. Commendations are also extended to the workshop of Fomoyi Services Nig. Ltd for their assistance during this study.

\section{References}

[1] Mothilal, T., Kaliappan, S., Kamal, R. M. D., and Roy, V. 2017. "Design of Turbocharger in Petrol Engine with Intercooler and Discharger Chamber.” International Journal of Latest Engineering and Management Research 2 (12): 81-7.

[2] Reddy, S. S. K., Pandurangadu, V., and Hussain, S. P. A. 2013. "Effect of Turbo Charging on Volumetric Efficiency in an Insulated Di Diesel Engine for Improved Performance." International Journal of Modern Engineering Research 3 (2): 674-7.
[3] Kech, J., Hegner R., and Mannle, T. 2014. Turbocharging: Key Technology for High-Performance Engines. Rolls-Royce: MTU Friedrichshafen GmbH.

[4] Williams, A. M., Baker, A. T., Garner, C. P., and Vijayakumar, R. 2013. "Turbo-Discharging Turbocharged Internal Combustion Engines.” Proceedings of the Institution of Mechanical Engineers Part D-Journal of Automobile Engineering 227 (D1): 52-65.

[5] Bhurat, S., Yadav, A., and Pathak, A. 2012. "Implementation of Turbocharger in Petrol Engines and Its Thermal Analysis.” International Journal of Advanced Computer Research 2 (4): 6.

[6] Rajeevan, J., Hans, M. H., Joseph, A., Kiran, T. S., and Thampi, G. K. 2016. "Hybrid Turbocharged SI Engine with Cooled Exhaust Gas Recirculation for Improved Performance.” Procedia Technology 24: 444-51.

[7] Mohd, M., Ahmad, M., and Sherwani, A. F. 2015. "Turbocharging of Diesel Engine for Improving Performance and Exhaust Emissions: A Review.” IOSR Journal of Mechanical and Civil Engineering 12 (4): 22-9.

[8] Yunus, A. C., and Michael, A. B. 2011. Thermodynamics: An Engineering Approach. New York: Mcgraw Hill Education.

[9] Mohd, M., and Manoj, K. 2013. "Turbocharging of IC Engine: A Review.” International Journal of Mechanical Engineering and Technology 4 (1): 142-9.

[10] Abdullah, U. 2010. "The Effects of Inter-Cooling on Performance of a Turbocharged Diesel Engine's Specific Fuel Consumption with Neural Network." Scientific Research and Essays 5 (23): 3781-93.

[11] Shaaban, S., and Seume, J. 2012. "Impact of Turbocharger Non-Adiabatic Operation on Enginevolumetric efficiency and Turbo Lag." International Journal of Rotating Machinery, Article ID 625453. 